\title{
Erratum to: Biomechatronics in Medical Rehabilitation
}

\author{
Shane Xie and Wei Meng
}

\section{Erratum to:}

S. Xie and W. Meng (eds.), Biomechatronics in Medical

Rehabilitation, https://doi.org/10.1007/978-3-319-52884-7

In the original version of the book, in Chapters 1-10, chapter author names have been included in the respective chapters and the workflow has been changed from Authored book to Edited book. The erratum book has been updated with the changes. 